\title{
Güvenlik İkliminin Güvenlik Performansına Olan Etkisi: Türkiye'deki Çalışanlar Arasında Bir Çalışma
}

\author{
Ahmet Ebrar Sakallı ${ }^{*}$, Sertaç Temur ${ }^{2}$, Mehmet Ali Badem $^{3}$, Ebru Karataş ${ }^{4}$ \\ 1* İstanbul Aydın Üniversitesi, Anadolu Bil Meslek Yüksekokulu, İş Sağlığı ve Güvenliği Progamı, İstanbul, Türkiye, (ORCID: 0000-0003-0445-0722), \\ ahmetsakalli@ aydin.edu.tr \\ 2 İstanbul Yeni Yüzyıl Üniversitesi, Sağlık Bilimleri Fakültesi, İş Sağlığı ve Güvenliği Bölümü, İstanbul, Türkiye (ORCID: 0000-0003-4845-1452), \\ sertac.temur@yeniyuzyil.edu.tr \\ 3 İzmir Kavram Meslek Yüksekokulu, Meslek Yüksekokulu, İş Sağlığı ve Güvenliği Programı, İzmir, Türkiye (ORCID: 0000-0001-6205-925X), \\ mehmet.badem@kavram.edu.tr \\ ${ }^{4}$ İstanbul Üniversitesi, Edebiyat Fakültesi, Psikoloji Bölümü, İstanbul, Türkiye (ORCID: 0000-0003-3933-0448), ebru.karatas@ ogr.istanbul.edu.tr
}

(İlk Geliş Tarihi 14 Kasım 2021 ve Kabul Tarihi 03 Ocak 2022)

(DOI: $10.31590 /$ ejosat.1023484)

ATIF/REFERENCE: Sakallı, A.E., Temur, S., Badem, M.A. \& Karataş, E. (2022). Güvenlik İkliminin Güvenlik Performansına Olan Etkisi: Türkiye'deki Çalışanlar Arasında Bir Çalışma. Avrupa Bilim ve Teknoloji Dergisi, (33), 93-106.

\section{Öz}

Güvenlik iklimi, güvenlik kültürünün bir alt boyutu olarak işletmelerde güvenli davranışları ve güvenlik tutumlarını etkileyen bir olgudur. Güvenlik performansı ise güvenlik ikliminin sonucu olarak işletmenin güvenlik seviyesini nicel olarak gösteren bir kavramdır. Literatürde yer alan çalışmalar incelendiğinde güvenli olmayan davranış, kazaların meydana gelmesindeki belirleyici faktörlerden biridir. Bu bağlamda, Neal, Griffin ve Hart tarafından geliştirilen güvenlik iklimi ve güvenlik performansı ölçeklerinin çeviri çalışması ve faktör analizi yöntemi ulusal literatürde ilk defa kullanılmıştır. Bununla birlikte yapısal eşitlik modeli (YEM) ve yol analiz yöntemleri kullanılarak iki kavram arasındaki korelasyonun incelenmesi amaçlanmıştır. Eğitim, sağlık, hizmet, sanayiüretim ve diğer olmak üzere toplam 6 sektörden 317 katılımcı katılım göstermiştir. Faktör analizi sonuçlarına bakıldığında faktör yüklerinin 0,40 ile 0,95 arasında olduğu görülmektedir. Güvenilirlik analizi sonuçları 0,91 ve 0,97 arasında görülmektedir. Orijinal ölçekten farklı olarak, yapılan analizler sonucunda ölçeğin toplam 36 soru ve 4 faktör oluştuğu sonucuna varılmıştır. Sonuç olarak, güvenlik iklimin güvenlik performansını etkilediği ve güvenlik bilgisinin hem doğrudan hem de dolaylı olarak, güvenlik motivasyonun ise doğrudan güvenlik performansı üzerine etkisi olduğu saptanmıştır. Bununla birlikte Türkiye'de İSG eğitimlerinin eğitim ve öğretimin her derecesinde yer verilmesi ve nitelik ve nicelik bakımından artırılması gerektiği ortaya çıkmıştır.

Anahtar Kelimeler: Güvenlik Kültürü, Güvenlik İklimi, Güvenlik Performansı

\section{The Impact of Safety Performance of The Safety Climate: Between Employees in Turkey}

\begin{abstract}
Safety climate, as a sub-dimension of safety culture, is a phenomenon that affects safe behaviors and safety attitudes in businesses. Safety performance, on the other hand, is a concept that quantitatively shows the safety level of the enterprise as a result of the safety climate. When the studies in the literature are examined, unsafe behavior is one of the determining factors in the occurrence of accidents. In this context, the translation study and factor analysis method of safety climate and safety performance scales developed by Neal, Griffin and Hart were used for the first time in the national literature. In addition, it is aimed to examine the correlation between the two concepts by using the structural equation model (SEM) and path analysis methods. 317 participants from 6 sectors including education, health, service, industry-production and other participated. Considering the results of factor analysis, it is seen that factor loads are between 0.40 and 0.95 . Reliability analysis results are seen between 0.91 and 0.97 . Unlike the original scale, as a result of the analysis, it was concluded that the scale consisted of 36 questions and 4 factors. As a result, it has been determined that the safety climate affects the safety performance, and that the safety knowledge both directly and indirectly, and the safety motivation directly affects the safety performance. However, it has emerged that OHS trainings in Turkey should be included in all levels of education and training and should be increased in terms of quality and quantity.
\end{abstract}

Keywords: Safety Culture, Safety Climate, Safety Performance

\footnotetext{
*Sorumlu Yazar: ahmetsakalli@aydin.edu.tr
} 


\section{Giriş}

Çalışanlardaki güvenlik iklimi seviyesi, bir örgütteki güvenli davranışlarını ve güvenlik tutumlarını etkileyen bir olgudur. Yapılan çalışmalara bakıldığında güvenlik ikliminin güvenlik performansının bir öncüsü olduğuna dair artan işaretler görülmektedir. Güvenli olmayan davranış, kazaların meydana gelmesindeki belirleyici faktörlerden biridir. Güvenlik performansının belirleyicileri, uyum ve katılımdaki bireysel farklılıklardan doğrudan sorumlu olan faktörlerini temsil eder.

Türkiye'de güvenlik iklimi ve güvenlik performans düzeyi konusunda birçok çalışma yapılmaktadır. $\mathrm{Bu}$ nedenle çeviri çalışması ile ölçek geliştirmek için ilk kez faktör analizi ve iki kavram arasındaki ilişkiyi incelemek üzere yapısal eşitlik modeli (YEM) ve yol analiz yöntemleri kullanılarak ulusal literatüre kazandırılmak amaçlanmıştır. Katılımcı sayısı belirlenirken uluslararası literatürde kabul görmüş çalışmalar göz önünde bulundurularak (Gorsuch, 1983; Kline, 1979; Tabachnick ve Fidell, 2007; Cattell, 1978; Norusis, 1994) rastgele olmak üzere toplam 317 katılımcı bu çalışmaya katılmıştır. Analiz sonuçlarına bakıldığında güvenlik ikliminin güvenlik performansı üzerine pozitif yönde bir etkisi olmasına karşın bilgi ve motivasyon düzeylerinin çalışanlardaki güvenlik performansını önemli derecede etkilediği görülmüştür.

Çalışmanın Amacı, Türkçe diline uyarlanmış geçerlilik ve güvenirlilik çalışması yapılmış bir çalışmasının kazandırılmasıdır. Yapılan ölçek uyarlaması, güvenlik iklimi ve güvenlik performansının arasındaki ilişkinin incelenmesi ve yapılacak sonraki çalışmalara ışık tutmasının sağlanılmasıdır.

\subsection{Kavramsal Çerçeve}

\subsubsection{Güvenlik İklimi}

Güvenlik kültürü kavramı tarihte 1986 yılında Çernobil'de meydana gelen nükleer santral kazasından sonra ilk kez 1987 tarihli OECD Nükleer Ajansı Raporunda bahsedilmiştir. (Cooper, 2000: 113). Güvenlik kültürü kavramı hakkında çeşitli tanımlamalar mevcut olsa da genel anlamda çalışanların, çalışma ortamının güvenliği ile ilgili paylaştıkları ortak inanç, tutum, alg1, değer ve davranış biçimleri olduğu noktasında fikir birliği bulunmaktadır (Cox\&Cox, 1991; Gellert, 1994; Guldenmund, 2000; INSAG, 1991; Pidgeon, 1991;).

İlk kez Zohar (1980) tarafından kullanılan ve "çalışanların işyerlerindeki çalışma ortamları hakkında paylaştıkları temel algıların tanımlamak için kullanılan bir terim" olarak ifade edilen güvenlik iklimi, bazı araştırmacılar tarafından (Mearns \& Flin, 1999; Cooper, 2000; Neal, Griffin \& Hart, 2000) "güvenlik kültürü" yapısının bir alt bileşeni olarak kabul edilmektedir. Güvenlik kültürü iş kazalarını önlemek ve azaltmak için birçok meslek grubu ve disiplin tarafından ele alınmıştır (Ensari Özay, Yılmaz \& Uçan, 2020). Patankar ve Sabin (2010), bir işyerindeki güvenlik kültürü yapısını dört basamaklı bir piramit üzerinde incelemek istemiştir (Şekil 1). Şekil 1'e göre 4 basamak içeren bu piramidin en alt basamağında "Temel Güvenlik Değerleri", ikinci basamağında "Örgütsel Faktörler" (güvenlik liderliği stratejileri, normlar), üçüncü basamağında "Tutumlar ve Fikirler" (güvenlik iklimi) ve piramidin en üst basamağında ise, güvenli davranışlar (güvenlik performansı) yer almaktadır. Bu çalışma güvenlik kültürünün alt bileşeni olan ve anket yöntemleriyle ölçülebileceğini dile getiren çalışanların güvenlik iklimini (algılarını) ve gözlemlenebilir güvenli davranışların bir çıktısı olan güvenlik performansı ilişkisini incelemektedir.

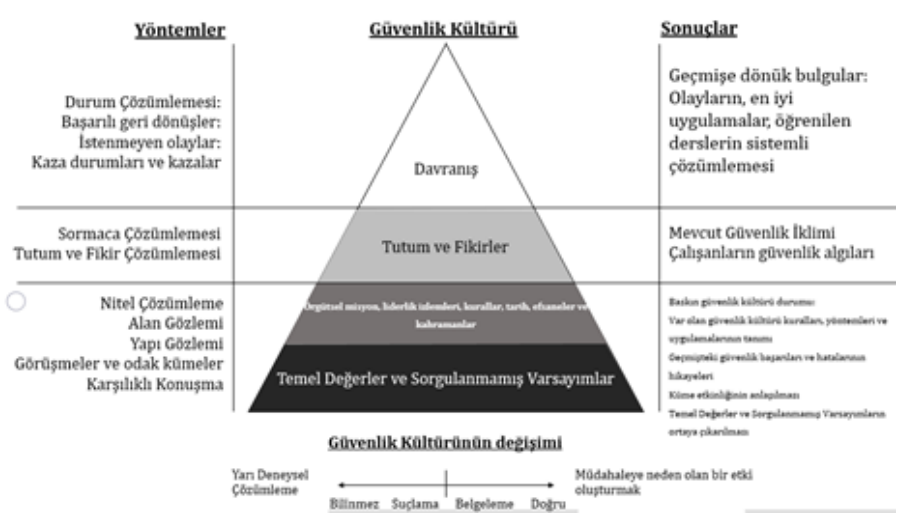

Şekil 1. Güvenlik Kültürü Piramidi (Patankar \& Sabin, 2010). (Figure 1. Pyramids of Safety Culture)

Güvenlik ikliminin boyutları olarak bir dizi faktör tanımlanmıştır. $\mathrm{Bu}$ faktörlere örnek vermek gerekirse yönetim değerleri (örn. Çalışan refahı için yönetim kaygısı), yönetim ve organizasyon uygulamaları (örn. Çalışanların eğitimin yeterliliği, güvenlik ekipmanlarının sağlanması, güvenlik yönetim sistemlerinin kalitesi), iletişim ve işyeri sağlığı ve güvenliğine çalışan katılımı. Bir dizi çalışma, bu faktörlerin iş sağlığ 1 ve güvenliği ile ilgili kazalar ve olaylar gibi sonuçları öngördüğünü göstermiştir (Neal, Griffin \& Hart, 2000; Zohar, 1980; Hofmann \& Stetzer, 1996). Ancak Tablo 1'de de görüldüğü gibi araştırmacılar arasında güvenlik ikliminin boyutları konusunda bir anlaşma yoktur.

Tablo 1. Güvenlik İklimi Boyutlarl Hakkında Yapılan Çalışmalara Örnekler (Table 1. Examples of the Studies About Safety Climate Dimensions)

\section{Yazarlar Güvenlik iklim boyutu}

Cox \& Cox, 1. Kişisel şüphecilik, 2. Bireysel dokunulmazlık, 1991 3. Bireysel sorumluluk, 4. Güvenlik planının etkinliği, 5. Çalışma ortamının güvenliği

Neal, 1. İletişim; 2. Yönetim değerleri; 3. Eğitim; 4. Griffin Hart, Güvenlik sistemleri

2000

Cooper \& 1. İşyerindeki risk seviyesi; 2. Yönetimin Phillips, güvenliğe yönelik tutumu; 3. Çalışma ritminin 2004 etkisi; 4. Güvenlik eğitiminin önemi; 5. Güvenliğin sosyal statü ve terfi üzerindeki etkisi; 6. Yükselişin etkisi; 7. Güvenlik görevlileri ve komitenin durumu

Barbaranelli 1. Yönetim değerleri; 2. İletişim; 3. Eğitim; 4. , Petitta \& Güvenlik sistemleri

Probst, 2015

Givehchi, 1. Yönetim güvenlik önceliği ve yeteneği; 2. 
Hemmativa Yönetim güvenliğinin güçlendirilmesi; 3. ghef \& Yönetim güvenliği adaleti; 4. Çalışanların Hoveidi, güvenlik taahhüdü; 5. Çalışanların güvenlik 2017 önceliği ve riskin kabul edilmemesi; 6. Güvenlik iletişimi, öğrenme ve iş arkadaşlarının güvenlik yeterliliğine güven; 7 . İşçilerin güvenlik sistemlerinin etkinliğine olan güveni

Güvenlik iklimi bir örgütteki çalışanlar tarafından algılanan güvenliğin önemini gösterir. Çalışandaki güvenlik iklimi seviyesi, bir örgütteki güvenli davranışlarını ve güvenlik tutumlarını etkilemektedir. Güvenlik algıları daha olumlu olduğunda, çalışanların tehlikeli eylemlerde bulunma olasılığ daha düşüktür ve bu da daha düşük kazalanma ve yaralanma ile sonuçlanır (Clarke, 2006). Son 35 yılda yapılan araştırmalar, güvenlik ikliminin, kazalar ve yaralanmalar gibi güvenlik davranışlarının ve güvenlik sonuçlarının önemli bir öngörücüsü olduğunu göstermektedir (Griffin \& Curcuruto,2016).

Uzun vadeli çalışmalar, güvenlik ikliminin güvenlik performansının bir öncüsü olduğuna dair artan bir işaret vardır (Clarke, 2010, 2006; Neal \& Griffin, 2006; Wallace, Popp \& Mondore, 2006). Ayrıca güvenlik iklimi bulgularının daha kesin olduğu ve kaza sayıları ile kaza ve olay araştırmalarından elde edilen reaktif (olayın ardından) verilerden ziyade güvenliği iyileştirmek için proaktif olduğu kabul edilir (Seo ve diğerleri, 2004).

\subsubsection{Güvenlik Performanst}

Güvenlik, her organizasyon için en temel sorundur ve doğrudan ve dolaylı maliyetler ve üretkenlik üzerinde önemli etkileri vardır (Clarke vd., 2015). Başarılı örgütlerin temel amaçlarından biri işyeri güvenliğinde sürekli iyileştirmedir. $\mathrm{Bu}$ nedenle, bir örgütün güvenlik performansını değerlendirmek, katkıda bulunan ve kontrol eden faktörleri belirlemekten çok önemlidir, çünkü her iyileştirme programında göstergelerin nicel ölçümleri kaçınılmazdır (Eskandari vd., 2020).

Güvenli olmayan davranış, kazanın meydana gelmesi için belirleyici bir faktördür (Reason, 1995; Sakallı, 2019). Çalışan tarafından algılanan güvenlik iklimi ile iş kazaları arasındaki ilişkiyi açıklamak için bir dizi psikolojik mekanizma önerilmiş olsa da bunların çoğunda örtük olan iklim $\rightarrow$ davranış $\rightarrow$ kaza modeli, bireylerin güvenlik iklimi algılarının performanslarını (davranışlarını) etkilemesidir (Neal \& Griffin, 2006; Neal, Griffin \& Hart, 2000; Clarke, 2010).

Griffin ve Neal, (2000) çalışma ortamında güvenli ve güvensiz davranışları ayırt etmek için aynı iki kategoriyi uygulamıştır. Güvenlik performansının iki boyuttan oluşmaktadır: uyum ve katılım. Uyum, güvenlik prosedürlerine bağlı kalmayı ve işi güvenli bir şekilde yürütmeyi içerir. Katılım ise iş arkadaşlarına yardım etmeyi, işyerinde güvenlik programını teşvik etmeyi, inisiyatif göstermeyi ve işyerinde güvenliği iyileştirmek için çaba göstermeyi içerir. Güvenlik performansının belirleyicileri, uyum ve katılımdaki bireysel farklılıklardan doğrudan sorumlu olan faktörleri temsil eder.

Güvenlik performansı davranışının iki biçimi arasındaki önemli ayırt edici faktör, uyumun görev içi görevle ilgili davranışı içermesi, güvenlik katılımının ise gönüllü ve çalışanlar tarafından başlatılan ekstra rol davranışlarını içermesidir (Clarke
\& Ward, 2006). Bazı araştırmalar her iki tür güvenlik performansı davranışının az sayıda işle ilgili kaza ve yaralanmalarla ilişkili olduğunu göstermektedir (Clarke, 2006).

Şekil 2'de görüldüğü gibi güvenlik iklimi algılarının bilgi ve motivasyon üzerindeki etkileriyle güvenlik performansını etkilediğini göstermektedir.

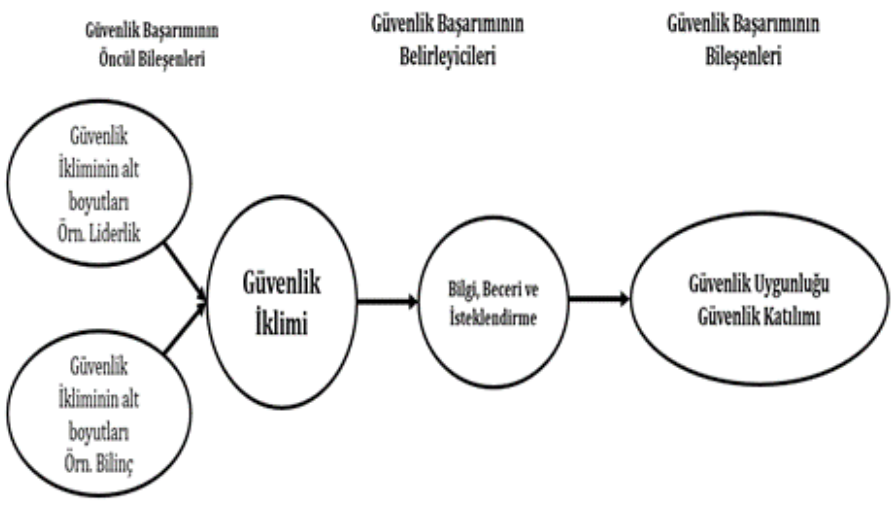

Şekil 2. Yapılar arasında varsayılmış ilişkiler (Neal, Griffin \& Hart, 2000). (Figure 2. Assumed relationships between structures)

İş performansı kuramları çerçevesinde geliştirmiş oldukları güvenlik performansı modeli, güvenlik ikliminin güvenlik performansı ile ilişkisini gözler önüne sermektedir. Performans bileşenleri, bireylerin gerçekleştirdiği davranışları temsil eder. Performans belirleyicileri, doğrudan davranıştaki bireysel farklılıklardan sorumludur. Performansın öncülleri, bilgi, beceri ve motivasyon üzerindeki etkileri yoluyla davranışı etkileyen faktörleri temsil eder (Griffin \& Neal, 2000). Yetenek, kişilik ve örgütsel iklim dahil olmak üzere iş davranışını etkilediği bilinen çok çeşitli bireysel ve çevresel faktörler vardır (Griffin \& Neal, 2000).

Güvenlik motivasyonu, bir çalışanın güvenlik davranışlarını gerçekleştirmek için çaba gösterme istekliliği olarak ifade edilebilir (Neal \& Griffin, 2006). Güvenlik motivasyonu, genellikle güvenlik iklimi gibi organizasyonel faktörlerin ortaya çıkardığı kişiyle ilgili bir faktör olarak kabul edilir (Griffin ve Curcuruto, 2016). Bu nedenle çalışanlar, çalışma ortamında olumlu bir güvenlik iklimi olduğunu algılarlarsa, güvenlikle ilgili davranışlarda bulunmaya motive olabilirler (Kim, Kim \& Lee, 2021). Güvenlik motivasyonunun amac1, bilimsel ilkeleri ve prosedürleri kullanarak istenen güvenlik düzeyinde kazaları ve yaralanmaları önlemektir. Güvenlik motivasyonu, güvenlik prosedürlerine bağlılığı etkiler ve sadece bireylerin değil, aynı zamanda kuruluşların ve hatta toplumun güvenliğini sağladığ bulunmuştur (Ying, Zhijia \& Lianbao, 2012).

\subsubsection{Hipotezler}

Yapılan analizlerde,

- Güvenlik ikliminin güvenlik performansı ile ilişkisinin doğrudan bir etkisinin olup olmadığı 
- Güvenlik ikliminin motivasyon ve bilgi aracılığıyla güvenlik performansına etkisinin olup olmadığı,

- Güvenlik ikliminin bilginin tek başına güvenlik performansına etkisinin yeterli olup olmadığg,

- Güvenlik ikliminin bilginin tek başına güvenlik performansına etkisinin yeterli olup olmadığı,

Güvenlik ikliminin güvenlik performansına olan etkisinin sektörler bazında bir farkın olup olmadığı,

- Güvenlik ikliminin güvenlik performansına olan etkisinin cinsiyet bazında bir farkının olup olmadığı,

- Güvenlik ikliminin güvenlik performansına olan etkisinin eğitim seviyeleri bazında bir farkının olup olmadığı

hipotezleri incelenmek istenmektedir.

\subsubsection{Etik Kurul Onayı}

Çalışmada kullanılan ölçekler, İstanbul Aydın Üniversitesi Sosyal Bilimler Etik Komisyonu'nun 1 Şubat 2021 tarihli 2021/1 toplantısının 30. kararı gereğince araştırmacılar tarafindan kullanılması komisyon üyeleri tarafınca uygun görülmüştür.

\section{Materyal ve Metot}

\section{1. Çeviri Çalışması}

Çeviri çalışmasına başlamadan önce “Güvenlik İklimi Ölçeği”ni geliştiren araştırmacilardan gerekli izinler için iletişime geçilip, ölçeği kullanmak adına onay alınmıştır. Ölçeğin İngilizce formu, İngilizce ve Türkçeyi iyi derecede bilen üç Psikoloji ve İş Sağlığı ve Güvenliği alan uzmanı tarafindan Türkçeye çevirisi yapılmıştır. Daha sonra bu Türkçe çeviriler üzerinden de İngilizceye çeviri gerçekleştirilmiş ve ölçeğin orijinal formu ile karşılaştırılarak çeviri-tekrar çeviri süreci tamamlanmıştır.

Yapılan bu çalışmada kullanılan güvenlik iklimi, güvenlik performansı, güvenlik motivasyon ve güvenlik bilgisi ölçekleri Türkçeye çeviri çalışmasında Brislin ve arkadaşlarının (1973) öne sürdüğü beş aşamadan oluşan teknik kullanılmıştır. Bu aşamalar, ilk çeviri, ilk çeviriyi değerlendirme, geri çeviri, geri çeviriyi değerlendirme ve uzman görüşünü içermektedir. Yapılan bu ölçekler öncelikle iki İngiliz Dili ve Edebiyatı dil bilimcisi tarafından Türkçe'ye çevrilmiştir. Elde edilen Türkçe ölçek farklı üç Psikoloji ve İş Sağlığı ve Güvenliği alan uzmanı tarafından değerlendirilmiştir. Ölçek uyarlama süreciyle ilgili olarak en önem arz eden sorunlardan birisi ölçeğin ana dilden farklı bir dil ve kültürde geliştirilmiş olmasıdır (Öner, 1996). Bu nedenle yalnızca madde çevirisi yeterli görülmemektedir. Bu değerlendirmede soruların anlaşılırlığı ve kültürel uygunluğu gözden geçirilmiş olup değerlendirme sonucunda elde edilen Türkçe ölçek, farklı iki İngiliz Dili ve Edebiyatı dil bilimcisi tarafından tekrar İngilizceye çevrilmiştir. Elde edilen İngilizce ölçek, özgün haliyle karşılaştırılmış ve son olarak üç Psikoloji ve İş Sağlığı ve Güvenliği alan uzmanı görüşüne sunulmuştur. Uzman değerlendirmeleri sonrasında ise uygulanan ölçeğin son hali ortaya çıkmış ve mevcut çalışmada kullanılması kararı alınmıştır.

\section{2. Örneklem}

Makalenin amacı dünyada ve ülkemizde güvenlik iklimini ve güvenlik performansını ölçmek için yaygın bir şekilde kullanılan, güvenlik iklimi kavramına yön verenler arasında bulunan Neal, Griffin ve Hart'ın 2000 yılında yapmış olduğu çalışmadaki ölçeklerinin geçerlilik ve güvenirlilik çalışmalarının yapılıp Türkçe diline uyarlanması ve güvenlik iklimi, güvenlik performansı düzeyleri ve aralarındaki ilişkiyi inceleyen bilgi ve motivasyon düzeylerini tespit etmektir.

Ülkemizde daha önceki çalışmalarda çeviri çalışması yapılarak kullanılan güvenlik iklimi ve güvenlik performansı ölçekleri için faktör analizi yapılmadığı görülmüştür. $\mathrm{Bu}$ nedenle güvenlik iklimi ve güvenlik performansı ölçekleri için ilk defa faktör analizi kullanılarak ölçekler analiz edilmiştir. Faktör analizi ile ilgili yapılan çalışmalarda gereken minimum örneklem büyüklüğü seçimi için sunulan önerilerin genel olarak iki kategoride toplandığı görülmektedir. Önerilerden biri mutlak örneklem büyüklüğünün önemli olduğunu ifade etmektedir (Doğan, Soysal \& Karaman, 2017). Bu yaklaşıma göre minimum örneklem büyüklüğünün Gorsuch (1983) ve Kline (1979) en az 100; Tabachnick ve Fidell (2007) en az 150; Cattell (1978) en az 250 ve Norusis (1994) en az 300 olmasını gerektiğini belirtmişlerdir. Comrey ve Lee (2013) ise örneklem büyüklüğünü belirlerken $100=$ zayıf, $200=$ orta, $300=$ iyi, $500=$ çok iyi ve $1000=$ mükemmel olacak şekilde bir sınıflandırma yapmıştır. Bazı araştırmacılar ise mutlak örneklem büyüklüğü yerine birey/değişken sayısı oranının önemli olduğunu belirtmiştir (Doğan, Soysal \& Karaman, 2017). Bu yaklaşıma göre birey/değişken oranı için Kline (2014), örneklem büyüklüğü 100'den az olmamak üzere birey/değişken oranının 10: 1 tutulmasinı ancak bu oranın en az 2: 1 kadar düşürülebileceğini dile getirmiştir. Child (2006) tarafından yapılan bir çalışmasında belirttiği üzere, faktör analizi tekniğinin kullanılabilmesi için gözlenen değişken sayısının veya çalışmada yer alan madde sayısının beş katı büyüklüğünde olması gerektiğini vurgulamıştır. Cattell (1978) bu oranın 3: 1 ile 6: 1 arasında olabileceği, Gorsuch (1983) ise 5: 1 oranının yeterli olabileceğini ifade etmiştir.

$\mathrm{Bu}$ çalışmada faktör analizinin yapılabilmesi için örneklem seçimi önerileri de baz alınarak Türkiye'nin çeşitli illerinden(İstanbul, İzmir, Antalya, Adana ve Ankara) hizmet, eğitim, sağlık, yapı işleri, sanayi ve serbest meslek çalışanlarından rastgele seçilen 317 gönüllü katılımcıdan oluşmaktadır. Toplanan verilerle ilgili olarak gönüllü kişilere Google Form üzerinden oluşturulan ilgili ölçek formları gönderilerek toplanmıştır.

\subsection{Veri Toplama Araçları}

\subsubsection{Sosyo-Demografi}

Cinsiyet, yaş, eğitim durumu, medeni hal, meslek, aylık gelir ve çocuk sahibi olma durumu göre demografik değişkenler değerlendirildi.

\subsubsection{Güvenlik İklimi Ölçeği}

Neal, Griffin ve Hart'ın 2000 yılında yapmış olduğu çalışmadaki güvenlik iklimi ölçeği kullanılmıştır. Bu ölçeğin Türkçe geçerlik ve güvenirlilik çalışmaları daha önce yapılmadığı için bu çalışmada 317 katılımcıdan toplanan verilerle açımlayıcı faktör analizi yapılmıştır. Ölçeğin orijinalinde bulunan alt boyutları; yönetim değerleri, iletişim, eğitim ve güvenlik sistemleri 
Katılımcılar ölçek maddelerini beşli likert ölçeği yardımıyla değerlendirmişlerdir (1= Kesinlikle Katılmıyorum, 5= Kesinlikle Katıliyorum).

Eğitim alt boyutu; örgüt tarafından çalışanlara sağlanan güvenlik eğitimi ile ilgili çalışanların algılarını, yönetim değerleri alt boyutu; çalışan refahı için yönetim endişesini, iletişim alt boyutu; çalışan ve yönetim arasında güvenlikle ilgili iletişim hakkında çalışanların algılarını değerlendirmektedir. Güvenlik sistemleri alt boyutu ise 3 sorudan oluşmaktadır. Çalışma ortamı faktörü ölçeğin orijinalinde anlamsız çıkmasına karşın bu çalışmada da faktör analizinde ele alınmıştır $(1=$ Kesinlikle Katılmıyorum, 5= Kesinlikle Katılıyorum).

\subsubsection{Güvenlik performansının belirleyicileri}

Güvenlik performansının belirleyicileri, Neal, Griffin ve Hart'ın 2000 yılında yapmış olduğu çalışmada ele aldığı güvenlik motivasyonu ve güvenlik bilgisi ölçekleridir. Güvenlik bilgisi ölçeği; güvenlik uygulamaları ve prosedürleri hakkındaki bilgilerini, güvenlik motivasyonu ölçeği; güvenlikle ilgili faaliyet prosedürlerini gerçekleştirmek için bireysel motivasyonu ölçmektedir (1= Kesinlikle Katılmıyorum, 5= Kesinlikle Kat1liyorum).

\subsubsection{Güvenlik performansının bileșenleri}

Güvenlik performansı bileşenleri, Neal, Griffin ve Hart'ın 2000 yılında yapmış olduğu davranış ölçeğinden oluşur. Güvenli davranış ölçeği, güvenlik uyumu ve güvenlik katılımı olmak üzere iki alt boyuttan oluşmaktadır $(1=$ Kesinlikle Katılmıyorum, 5= Kesinlikle Katıliyorum).

\subsection{Veri Analizi}

Yapılan bu çalışmada demografik özelliklerinin analizi, faktör analizi ve güvenirlik analizi işlemleri için SPSS 25 analiz programı kullanılmıştır. Yapısal eşitlik modeli, yol analizi ve moderatör analizleri için IBM SPSS AMOS 26.0 analiz programı kullanılmıştır.

\subsubsection{Yapısal Eşitlik Modeli}

Yapısal eşitlik modellemesi (YEM), gözlenen ve gizil değişkenler arasındaki ilişkiler hakkındaki hipotezleri test etmek için kapsamlı bir istatistiksel yaklaşım sunmaktadır. YEM, diğer yaklaşımlardan (korelasyon, çoklu regresyon ve ANOVA gibi) daha esnek ve kapsamlıdır (Hoyle, 1995). Yapısal eşitlik modelinin yaygınlaşmasındaki bir diğer önemli etken ise ölçüm hatalarını en aza indirgeyebilmektir (Uca, 2016).

YEM'i kullanacak araştırmacı, kurumsal yapıyı veya modeli kurarken özgün olmalıdır. Ancak araştırmacı bu modeli ya da yapıyı oluştururken geçmişte yapılan araştırmalardan da faydalanabilmektedir. Yapısal eşitlik modeli ile yapılacak araştırmalarda öncelikle bu modelleme yapılmalıdır. Değişkenler arasındaki ilişki ve bu ilişkilerin yönleri kuramsal olarak belirlenir. Kuramsal yapıdaki ilişkilerin tamamı tanımlandıktan sonra toplanan verilerin bu ilişkileri destekleyip desteklemediği istatistiksel yöntem ve analizlerle test edilir (Kaynak, 2012).

Yapısal eşitlik modelleri, oluşturulan yapıdaki gizil boyutlar arasındaki açıklayıcı ilişkilere ait kuramsal iddiaların kabul edilebilir olup olmadığını test eder. Diğer bir ifade ile yapısal eşitlik modellerinde teoride var olan kavramsal model, veri yardımı ile test edilmeye çalışılır (Raykov \& Marcoulide, 2006; Kline, 2005). Bu çalışmada, YEM analizi için IBM SPSS AMOS Sürüm 26.0 kullanılmıştır.

\subsubsection{Yol Analizi}

Gözlenen(ölçülen) değişkenler arasındaki ilişki ağlarını inceleyen analiz yöntemine "Yol Analizi" denilmektedir (Kline, 2015). Yol analizindeki amaç, değişkenler arasında olduğu varsayılan ilişkinin önemini ve büyüklügünü tahmin ederek, çıkarımlarda bulunmaktır. Yol analizi çoklu regresyon modellerinin bir uzantısı olarak oluşmuştur. Yol analizinde sadece değişkenler arasındaki nedensellik değil, bununla birlikte nedensel modelleme (causal modelling) olarak adlandırılan yöntem kullanılarak değişkenler arasındaki ilişkiler araştırılıp tahmin edilebilmektedir (Schumacker \& Lomax, 2010: 143).

Yol analizi, diğer analiz türlerine göre daha karmaşık modelleri analiz etmek için daha uygundur çünkü modeller üretmek için hem doğrudan hem de dolaylı etkiler incelenebilir ve aynı anda faktörler arasındaki çoklu ilişkiler analiz edilebilir (Kim, Sok \& Won, 2021). Yol analizi ile regresyon analizi arasında benzerlik olsa da bazı özellikleri ile regresyon analizinden ayrışmaktadır. $\mathrm{Bu}$ özelliklerden biri regresyon analizinde bağımlı değişken sayısı her zaman bir tanedir. Buna karşın yol analizinde ise birden fazla bağımlı değişkenin eşzamanlı olarak tanımlanabilmektedir.

\subsubsection{Düzenleyici (Moderatör) Regresyon Analizi}

Düzenleyici (moderatör) değişken en basit anlamında değişkenler arasındaki (bağımlı ve bağımsız) ilişkinin gücünü veya yönünü belirleyen değişken olarak belirtilmektedir (Baron \& Kenny, 1986). Bir başka deyişle düzenleyici değişken, değişkenler arasındaki ilişkinin gücünü artırabilir, azaltabilir ya da bu ilişkinin yönünü pozitifse negatif; negatif ise pozitif yönde değiştirebilir. Düzenleyici değişkenler birçok kategoride olabilir. Örneğin bazı durumlarda cinsiyet, eğitim durumu, medeni hal vb. gibi sürekliliği olmayan kategoriler olabileceği gibi, beden kitle indeksi, kilo, boy, maaş, gibi sürekli olan-kesikli kategoriler de olabilir. Düzenleyici etki ise iki değişken arasındaki ilişkinin üçüncü bir değişkenin aldığı değerlere göre gösterdiği değişim olarak tanımlanabilir.

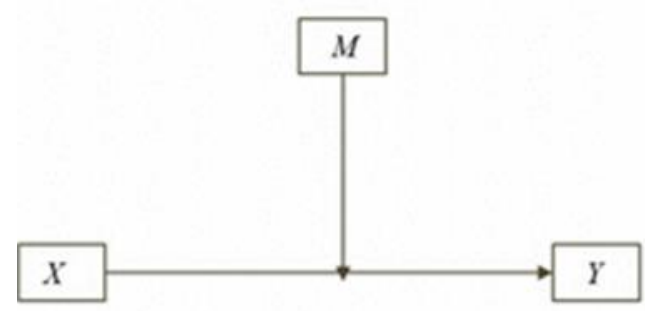

Şekil 3. Basit Moderatör Değişken (Sardeshmukh \& Vandenberg, 2017). (Figure 3. Basic Moderator)

Şekil 3'te gösterildiği gibi üçüncü bir değişken olan $M$ (moderatör değişkenler) $\mathrm{X}$ (yordayııı değişkenler) ve Y (sonuç değişkenleri) arasındaki ilişkinin gücünü etkilediğinde moderasyon gerçekleşir. Başka bir deyişle, iki değişken ( $\mathrm{X}$ ve $\mathrm{Y}$ ) arasındaki ilişkinin gücü, üçüncü bir moderatör olan $M$ değişkenin doğrudan bir fonksiyonu olarak değişir.

$\mathrm{Bu}$ çalışmada sadece süreksiz-kategorik düzenleyici moderatör ile regresyon analizi yapılmıştır.

\subsubsection{Uyum Kriter Testler}


$\mathrm{Ki}-\operatorname{kare}\left(\mathrm{x}^{2}\right)$ analizi, uygulanan modelin uyumunu test eden en temel ölçüm yöntemlerinden birisidir. Ki-kare, kavramsal olarak bu uyum ölçülen kovaryans matrisi ve model kovaryans matrisi arasındaki farkın ve örneklem hacminin bir fonksiyonudur. Kikare istatistiği örneklemin büyüklüğüne göre değişiklik göstermektedir. Bu analiz, büyük örneklem $(\mathrm{N} \geq 200)$ değerlerinin olduğu ölçümlerde anlamlı sonuçlar vermektedir. Bu nedenle kikare serbestlik derecesi oranı $X^{2} / s d$ (CMIN/DF) * modelin uyumu olarak bir değerlendirme sağladığı ifade edilmektedir (Bayram, 2010).

Modelin uyumunu belirleyen birçok uyum indeksi bulunmaktadır. Bu çalışmada yer verilen uyum indeksleri;

Kalıntılara dayanan uyumluluk indekslerinden biri olan Goodness of fit index(GFI) model tarafindan açıklanan varyans ve kovaryansın miktarının indeksidir. GFI değeri örneklem sayısı ile ilişkili olduğundan örneklem sayısı arttıkça GFI değeri de artış görülmektedir. GFI değeri 0 ile 1 arasında değişmektedir. GFI'ın $0,90 \leq$ GFI $<0,95$ arasındaki değerlerde olması "kabul edilir"; $0,95 \leq \mathrm{GFI} \leq 1,00$ arasındaki değerlerde olması durumunda "iyi uyum" göstergesi olarak tanımlanmaktadır. $\mathrm{Bu}$ durum gözlenen değişkenler arasında kovaryansın hesaplandığ anlamina gelmektedir. (MacCallum \& Sehee, 1997; Bayram, 2010).

GFI denklem Eş. (1);

$G F I=1-\left(\frac{X_{m}^{2}}{X_{b}^{2}}\right)$

$m$; test edilen modeli, $b$; bağımsız modeli göstermek üzere GFI uyum indeksi yukarıdaki gibi hesaplanır.

Comparative fit index (CFI) ise bağımsız modele dayanan uyum indeksleri içinde CFI en fazla kullanılan indeks değeridir. CFI değeri 1'den büyük çıkarsa 1 gibi değerlendirilir. CFI, 0-1 aras1 değişen değerler alır. $0,95 \leq \mathrm{CFI}<0,97$ arası değerler kabul edilir uyumu; 0,97 $\leq \mathrm{CFI} \leq 1$ iyi uyumu gösterir (Bayram, 2010).

CFI denklem Eş. (2);

$C F I=1-\frac{X_{m}^{2}-s d_{m}}{X_{b}^{2}-s d_{b}}$

$m$; test edilen modeli, $b$; bağımsız modeli, $s d$; serbestlik derecesini göstermek üzere GFI uyum indeksi yukarıdaki gibi hesaplanır.

Korelasyon ölçümündeki kalıntıların karelerinin toplamının kare kökü, Standardized Root Mean Square Residual (SRMR) yani standardize edilmiş kalıntıların ortalama kare kökü olarak ifade edilmektedir (Bayram, 2010). Başka bir deyişle gözlenen ve tahmin edilen kovaryanslar arasındaki standardize edilmiş farkı ifade etmektedir. Yapılan ölçümün sonucunun sıfıra yakın olması kovaryanslar arasındaki mükemmel uyumu göstermektedir. 0,05 'in altındaki değerler de iyi bir uyumu gösterirken $0,05 \leq$ SRMR $\leq 0,10$ kabul edilebilir uyumu ifade etmektedir (Bayram, 2010).

SRMR denklem Eş. (3);

$S R M R=\sqrt{\frac{2}{p(p+1)} \sum_{i \leq j}\left\{\left(s_{i j}-\sigma_{i j}(\theta)\right)\right\}^{2} / s_{i i} s_{j j}}$

Yukarıdaki formülde, $\sigma_{i j}(\theta) ; \sum \theta$ nin $(\mathrm{i}, \mathrm{j})$ ninci elemanıdır.
Yaklaşık hataların ortalama kara kökü (root mean square error of approximation) (RMSEA) 0,05'ten küçük değerler "iyi” uyumu gösterirken, 0,05 ile 0,10 arasındaki değerler "kabul edilebilir" uyumu gösterir (Browne \& Cudeck, 1992). Uyum ölçüleri arasında muhtemelen en popüler olanı RMSEA'dır (Jackson, Gillaspy \& Purc-Stephenson, 2009).

RMSEA denklem Eş. (4);

$R M S E A=\sqrt{\left.\left(x^{2} / s d-1\right) /(N-1)\right)}$

\section{Araştırma Sonuçları ve Tartışma}

Çalışmanın bulgular kısmında demografik bilgilere, çeviri çalışmasına, faktör ve geçerli güvenilirlik analizlerine, yapısal eşitlik modellemesine, yol analizine ve son olarak moderatör analizlerine yer verilmiştir.

\subsection{Demografik Bilgiler}

Tablo 2'de görüldüğü üzere 317 katılımcının \%56,2'ü (178) kadın ve \%43,8'i (139) erkektir.317 katılımcının \%42,6's1 (135) 18-25 yaş aralığında, \%36,9'u (117) 26-35 yaş aralığında, \%12,6'sı (40) 36-45 yaş aralığında, \%6,6'sı (24) 46-55 yaş aralığında, \%1,3'ü (4) ise 55 yaş üzeri katılımcılardan oluşmaktadır. Aylık gelirlerine göre gruplandırıldığında 317 katılımcının \%20,2' si (64) 2000€ ve altı aylık gelire, \%28,1'i (89) 2001£-3000£ aras1 aylık gelire, \%18'i (57) 3001£-4000£ arası aylı gelire, \%10,4'ü (33) 4001€-5000£ arası aylık gelire, $\% 10,7$ 'si (34) 5001£-6000€ aras1 aylı gelire ve \%12,6's1 (40) ise $6000 €$ üzerinde aylık gelire sahiptir. 317 katılımcının $\% 3,8$ 'i (12) ilkokul mezunu, \%4,4'ü (14) ortaokul mezunu, \%13,2'si (42) lise mezunu, \%18'i (57) ön lisans mezunu, \%40,7'si (129) lisans mezunu ve \%19,9'u (63) ise lisansüstü eğitim programlarından mezun katılımcılardan oluşmaktadır. 317 katılımcının \%30,9'u (98) evli ve \%69,1'i (219) bekar kişilerden oluşmaktadır. Katılımcı profilinin genel sektörlere göre dağılımına baktığımızda ise \%14,2'si eğitim sektöründen (45), \%13,7'si sağlık sektöründen (43), \%21,8'i hizmet sektöründen (69), \%13,7'si yapı sektöründen (43), \%16,4'ü sanayi ve üretim sektöründen (52), \%20,8'i ise (66) diğer sektörlerdendir.

Tablo 2. Demografik Bilgiler Tablosu (Table 2. Demographic Information)

\begin{tabular}{|c|c|c|c|}
\hline \multicolumn{2}{|c|}{ Değişken (N=317) } & \multirow{2}{*}{$\begin{array}{l}\text { Frekans } \\
139 \\
\end{array}$} & \multirow{2}{*}{$\begin{array}{l}\% \\
43,8 \\
\end{array}$} \\
\hline & Erkek & & \\
\hline Cinsiyet & Kadın & 178 & 56,2 \\
\hline \multirow{9}{*}{ Yaş } & $18-25$ & 135 & 42,6 \\
\hline & $26-35$ & 117 & 36,9 \\
\hline & $36-45$ & 40 & 12,6 \\
\hline & $46-55$ & 24 & 6,6 \\
\hline & $55+$ & 4 & 1,3 \\
\hline & 2000€ Alt1 & 64 & 20,2 \\
\hline & 2001€-3000€ & 89 & 28,1 \\
\hline & 3001€-4000€ & 57 & 18 \\
\hline & 4001€-5000€ & 33 & 10,4 \\
\hline
\end{tabular}




\begin{tabular}{|c|c|c|c|}
\hline \multirow{2}{*}{$\begin{array}{l}\text { Aylık } \\
\text { Gelir }\end{array}$} & 5001€-6000€ & 34 & 10,7 \\
\hline & 6000€ Üzeri & 40 & 12,6 \\
\hline \multirow{6}{*}{$\begin{array}{l}\text { Eğitim } \\
\text { Durumu }\end{array}$} & İlkokul & 12 & 3,8 \\
\hline & Ortaokul & 14 & 4,4 \\
\hline & Lise & 42 & 13,2 \\
\hline & Ön lisans & 57 & 18 \\
\hline & Lisans & 129 & 40,7 \\
\hline & Lisansüstü & 63 & 19,9 \\
\hline \multirow{2}{*}{$\begin{array}{l}\text { Medeni } \\
\text { Durum }\end{array}$} & Evli & 98 & 30,9 \\
\hline & Bekar & 219 & 69,1 \\
\hline \multirow{2}{*}{$\begin{array}{l}\text { Çocuk } \\
\text { Sahibi } \\
\text { Olma }\end{array}$} & Evet & 88 & 17,8 \\
\hline & Hayır & 229 & 72,2 \\
\hline \multirow{6}{*}{ Sektör } & Eğitim & 45 & 14,2 \\
\hline & Sağllk & 43 & 13,7 \\
\hline & Hizmet & 69 & 21,8 \\
\hline & Yap1 & 43 & 13,7 \\
\hline & Sanayi-Üretim & 52 & 16,4 \\
\hline & Diğer & 66 & 20,8 \\
\hline
\end{tabular}

18. İşyeri güvenliğindeki aksaklıkları önlemek için sistematik kurallar mevcuttur.

19. $\mathrm{Bu}$ organizasyondaki iş güvenliği kuralları ve uygulamaları yararlı ve etkilidir.

\section{Iletisim (Güvenlik İklimi Alt Bovut)}

6. Çalı̧̧anlar, iş güvenliği konularıyla ilgili endişelerini yöneticiler ile tartı̧̧abilirler.

7. Toplantılarda iş güvenliği sorunlarını tartışmak ve çözümlemek için yeterli firsatlar verilir.

8. Bu işyerinde iş güvenliği sorunları hakkında açık bir iletişim söz konusudur

9. Çalışanlarla işyerindeki sağlık ve güvenlik konuları hakkında düzenli olarak görüşmeler yapıılır

10. Eğitim programlarında iş güvenliği konularına yüksek öncelik verilmektedir.

\section{Güvenlik Motivasyonu}

28. Etiketleme / kilitleme kurallarına bağlı kalmanın faydalı olduğunu düşünüyorum.

29.Genel iş sağlığı ve güvenliği kurallarını uygulamanın her zaman önemli olduğuna inanıyorum.

30. Uygun kişisel koruyucu donanımı sürekli kullanmanın önemli olduğuna inanıyorum.

\subsection{Faktör Analizi ve Geçerli Güvenirlilik Analizi}

Açımlayıcı faktör analizi (AFA): Ölçeğin Türkçe formu 317 yetişkin çalışan kişilere uygulanmıştır. SPSS veri girişi tamamlandıktan sonra açımlayıcı faktör analizi yapılmıştır. Araştırmanın faktör analizi orijinal 46 maddelik form üzerinden yapılmıştır. Yapılan faktör analizi sonucunda ölçeğin orijinal ölçekten farklı olarak altı faktörlü bir yapıda olduğu ve toplam varyansın \%53'ünü açıkladığı görülmüştür (Tablo 3). Birden fazla faktöre yön veren ve hiçbir faktör yük vermeyen maddeler $(5,11,12,13,17,24,25,26,27)$ ölçekten çıkarılmış ve yeniden faktör analizi yapılmıştır. Bir faktörün çok kararlı olabilmesi için en az 3 tane maddeye sahip olması gerekmektedir (Velicer ve Fava, 1998; Büyüköztürk, 2002; Hogarty vd., 2005). Bu nedenle dördüncü faktöre sadece iki madde yüklendiği için (14 ve 16) çıkarılmıştır. Ölçeğin faktör analizi soruları ve sonuçları Tablo 3 ve 4 'te yer almaktadır:

\section{Tablo 3. Ölçek Soruları (Table 3. Scale Questions)}

\section{Güvenlik İklimi}

\section{Yönetim Değerleri (Güvenlik İklimi Alt Bovut)}

1. Yönetim, çalışanların iş güvenliğiyle ilgili ve alakalıdır.

2.Yönetimin işyerindeki İş Sağlığı ve Güvenliği üzerindeki etkisi güçlüdür

3. İş güvenliği, yönetim tarafindan yüksek öncelik verilen bir konudur.

\section{Yönetim, iş güvenliğini önemli sayar.}

15. Çalışma ortamı güvenlidir.

31. Kişisel koruyucu donanımların belirtilen alanlarda kullanılmasının faydalı olduğuna inanıyorum.

32. Genel iş sağlığı ve güvenliği kurallarına bağlı kalmanın işimde önemli olduğunu inanıyorum.

33. Genel iş sağlığı ve güvenliği kurallarının geliştirilmesine dahil olmanın faydalı olduğunu düşünüyorum.

34. İş sağlığı ve güvenliği programını desteklemenin önemli olduğuna inanıyorum.

35. Başkalarını güvenli çalışmaya teşvik etmenin önemli olduğunu düşünüyorum.

36. İş sağlı̆̆ı ve güvenliğinin devamlılığını sağlamak için fazladan çaba göstermenin faydalı olduğuna inanıyorum.

37. İş sağlığı ve güvenliği ile ilgili görevler için gönüllü olmanın faydalı olduğunu düşünüyorum.

38. Çalışma arkadaşlarıma güvensiz veya tehlikeli koşullarda yardım etmenin önemli olduğuna inanıyorum.

\section{Güvenlik Bilgisi}

20. İşimde nasıl güvenli bir şekilde çalışmam gerektiğini biliyorum

21. İş güvenliği ekipmanlarını nasıl kullanacağımı ve temel çalışma kurallarını biliyorum

22. İşyerinde sağlık ve güvenliği nasıl sağlayacağımı ya da geliştireceğimi biliyorum.

23. İşyerindeki kaza risklerini nasıl azaltacağımı biliyorum.

Güvenlik Performansı- Güvenlik Davranışı

Güvenlik Uyumu /Güvenlik Davranısı Alt Bovut] 
39. İşimi güvenli bir şekilde yaparım.

40. İşimi yapmak için gerekli tüm güvenlik ekipmanlarını kullanırım.

41. İşimi yaparken uygun iş güvenliği kurallarını uygularım.

42. İşimi yaparken iş güvenliğinin en üst seviyede olduğundan emin olurum

\section{Güvenlik Katılımı /Güvenlik Davranıșı Alt Bovut]}

43. İşyerindeki iş güvenliği uygulamalarını desteklerim.

44. İşyerindeki güvenliği artırmak için fazla çaba sarf ederim.

45. Çalışma arkadaşlarıma riskli veya tehlikeli koşullarda çalışırken yardımcı olurum.

46. İşyerindeki güvenliği artırmaya yardımcı olan görevleri veya faaliyetleri gönüllü olarak yerine getiririm.

Tablo 4. Çalışmada Kullanılan Ölçeklerin Faktör Analizi Sonuçlarl (Table 4. Factor Analysis Results of the Scales Used in the Study)

\begin{tabular}{|c|c|c|c|c|c|}
\hline$\underline{\text { No }}$ & Motivasyon & $\underline{\text { İletișim }}$ & $\underline{\text { Davran1s }}$ & $\underline{\text { Bilgi }}$ & $\frac{\text { Yönetim }}{\text { Değerleri }}$ \\
\hline 1. & & & & & 0,76 \\
\hline 2. & & & & & 0,77 \\
\hline 3. & & & & & 0,74 \\
\hline 4. & & & & & 0,83 \\
\hline 6. & & 0,79 & & & \\
\hline 7. & & 0,84 & & & \\
\hline 8. & & 0,80 & & & \\
\hline 9. & & 0,85 & & & \\
\hline 10. & & 0,52 & & & \\
\hline 15. & & & & & 0,53 \\
\hline 18. & & & & & 0,44 \\
\hline 19. & & & & & 0,40 \\
\hline 20. & & & & 0,81 & \\
\hline 21. & & & & 0,86 & \\
\hline 22. & & & & 0,85 & \\
\hline 23. & & & & 0,83 & \\
\hline 28. & 0,78 & & & & \\
\hline 29. & 0,87 & & & & \\
\hline 30. & 0,95 & & & & \\
\hline 31. & 0,90 & & & & \\
\hline 32. & 0,81 & & & & \\
\hline 33. & 0,90 & & & & \\
\hline 34. & 0,90 & & & & \\
\hline 35. & 0,94 & & & & \\
\hline
\end{tabular}

\begin{tabular}{l|l|l|l|l|l}
36. & 0,90 & & & & \\
\hline 37. & 0,91 & & & & \\
\hline 38. & 0,73 & & & & \\
\hline 39. & & & 0,77 & & \\
\hline 40. & & & 0,86 & & \\
\hline 41. & & & 0,84 & & \\
\hline 42. & & & 0,94 & & \\
\hline 43. & & & 0,80 & & \\
\hline 44. & & & 0,91 & & \\
\hline 45. & & & 0,86 & & \\
\hline 46. & & & 0,88 & &
\end{tabular}

Kişinin iş sağlığı ve güvenliğine dair motivasyonunu ölçmeyi hedefleyen motivasyon alt boyutu " İş sağlığı ve güvenliği programını desteklemenin önemli olduğuna inanıyorum." Gibi 11 maddeden oluşmaktadır. Katılımcıların iş sağlığı ve güvenliği sürecindeki iletişim algısına dair " Çalışanlar, iş güvenliği konularıyla ilgili endişelerini yöneticiler ile tartışabilirler. "' benzeri maddeleri içeren iletişim alt boyutu ise 5 maddeden oluşmaktadır. Kişilerin iş sağlığı ve güvenliği davranışlarını içeren davranış alt boyutu " İşimi yaparken iş güvenliğinin en üst seviyede olduğundan emin olurum." Gibi sekiz maddeden oluşmaktadır. Kendi içerisinde güvenlik uyumu (39, 40, 41 ve 42. Maddeler) ve güvenlik katılımı (43, 44, 45 ve 46. Maddeler) olmak üzere iki alt boyutu mevcuttur. Bilgi alt boyutu ise ", İşyerindeki kaza risklerini nasıl azaltacağımı biliyorum.”' Gibi 4 maddeden oluşmaktadır. Son olarak "' İş güvenliği, yönetim tarafindan yüksek öncelik verilen bir konudur." Maddelerden oluşan yönetim değerleri alt boyutu ise 7 maddeden meydana gelmiştir. Ölçeğin orijinalinde 10. Madde eğitim sorusunda olmasına rağmen Türkçe uyarlamasında 10. Madde iletişim faktöründe bulunmuştur. Yine ölçeğin orjinalinde 15. Madde çalışma ortamında, 18. Ve 19. Madde iş güvenliği sisteminde olmasına rağmen yönetim faktöründe bulunmuştur. Değişen maddelere bakıldığında ilgili faktörü tanımlayabilecek yakın ilişkiler bulunan maddelerdir.

Güvenirlik çalışması: Uyarlama çalışması yapılan 'Güvenlik İklimi Ölçeği'nin Cronbach Alfa katsayısı 0,97 olarak hesaplanmıştır. Motivasyon, İletişim, Davranış, Bilgi ve Yönetim Değerleri alt boyutlarına ilişkin güvenirlik analizi sonuçları Tablo 5 'te gösterilmektedir.

Tablo 5. Ölçeklerin Alt Boyutlarına İlişkin Güvenirlik Analizi Sonuçları (Table 5. Reliability Analysis Results Regarding the Sub-Dimensions of the Scales)

\begin{tabular}{l|l|l}
\hline Ölçek Boyutları & $\begin{array}{l}\text { Madde } \\
\text { Sayısı }\end{array}$ & Cronbach Alfa Katsayısı \\
\hline Motivasyon* & 11 madde & 0,97 \\
\hline
\end{tabular}




\begin{tabular}{l|l|l}
\hline İletişim** & 5 madde & 0,92 \\
\hline Davranı̧̧*** & 8 madde & 0,97 \\
\hline Bilgi* & 4 madde & 0,94 \\
\hline Yönetim Değerleri** & 7 madde & 0,91 \\
\hline
\end{tabular}

*Motivasyon ve Bilgi= Güvenlik performansının belirleyicileri (moderatör), ** Iletişim ve Yönetim Değerleri $=$ Güvenlik iklimi ölçeği, ***Davranış (Uyum ve Katılım) = Güvenlik performansı ölçeği

Not: Cronbach Alfa Katsaylsl eğer, $0<R_{2}<0.40$ ise güvenilir değil; $0,40<R_{2}<0.60$ ise düşük güvenilirlikte; $0.60<R_{2}<0.80$ ise oldukça güvenilir; $0,80<R_{2}<1.00$ ise yüksek güvenilirlikte olduğunu göstermektedir (Uzunsakal \& Yıldız, 2018).

Tablo 5'te görüldüğü gibi çalışmada kullanılan bütün ölçek boyutları $0.80<\mathrm{R}_{2}<1.00$ aralığında olduğundan dolayı yüksek güvenirliliktedir.

\subsection{Korelasyon Analizi}

Tablo 6. Değişkenler Arası İlişkiler (Table 6. Relationships Between Variables)

\begin{tabular}{l|l|l|l|l|l|l} 
& GP & GK & GU & Gi & $\mathbf{E}$ & $\mathbf{C}$ \\
\hline $\begin{array}{l}\text { Davranı̧̧ } \\
(\text { GP) } \\
\text { (Güvenlik } \\
\text { Performans1 } \\
)\end{array}$ & & $0,97^{* *}$ & $\begin{array}{l}0,97^{*} \\
{ }^{*}\end{array}$ & $\begin{array}{l}0,57^{*} \\
{ }^{*}\end{array}$ & $\begin{array}{l}0,15^{*} \\
{ }^{*}\end{array}$ & $-0,15^{* *}$ \\
\hline $\begin{array}{l}\text { Güvenlik } \\
\text { Katılımı } \\
\text { (GK) }\end{array}$ & & & $0,88^{*}$ & $\begin{array}{l}0,53^{*} \\
*\end{array}$ & $0,14^{*}$ & $-0,14^{*}$ \\
\hline $\begin{array}{l}\text { Güvenlik } \\
\text { Uyumu } \\
\text { (GU) }\end{array}$ & & & & $\begin{array}{l}*, 59^{*} \\
*\end{array}$ & $0,16^{*}$ & \\
\hline
\end{tabular}

Güvenlik performansı ile güvenlik katılımı, güvenlik uyumu ve güvenlik iklimi arasında pozitif yönde anlamlı bir ilişki vardır. Bunun yanında eğitim düzeyi arttıkça güvenlik performansı da anlamlı düzeyde artmaktadır. Kadınların güvenlik performansı erkeklere göre daha anlamlı düzeyde daha yüksektir.

Güvenlik katılımı ile güvenlik uyumu ve güvenlik iklimi arasında pozitif yönde anlamlı bir ilişki vardır. Bunun yanında eğitim düzeyi arttıkça güvenlik katılımı da anlamlı düzeyde artmaktadır. Kadınların güvenlik katılımı erkeklere göre anlamlı düzeyde daha yüksektir.

Güvenlik uyumu ile güvenlik iklimi arasında pozitif yönde anlamlı bir ilişki vardır. Eğitim düzeyi arttıkça güvenli uyumu da anlamlı düzeyde artmaktadır.

\subsection{Yol Analizi}

Tablo 7. Yol Analizinin Uyum Kriterleri ve Indeksleri Tablosu (Table 7. Table of Fit Criteria and Indexes of Path Analysis)

\begin{tabular}{lllllll} 
Model & $\begin{array}{l}\mathrm{CMI} \\
\mathrm{N}\end{array}$ & $\mathrm{DF}$ & $\mathrm{P}$ & $\begin{array}{l}\mathrm{CMIN} / \\
\mathrm{DF}\end{array}$ & $\mathrm{GFI}$ & $\mathrm{CFI}$ \\
$\begin{array}{l}\text { Varsayılan } \\
\text { model }\end{array}$ & 0,00 & 0 & $*$ & & 1,000 & 1,000 \\
\hline
\end{tabular}

* p değerinin 0,01'den küçük olduğunu ifade eder.

Ki kare dağılımlarında, değişkenin minimum değeri 0 (sıfır)'dır. Diğer bir deyişle $\mathrm{CMIN}=0$ olası en iyi uyumdur. $\mathrm{Ki}$ kare değişkeninin beklentisi, serbestlik derecesine eşittir. Diğer bir deyişle, doğru bir model için CMIN'in DF'ye yakın olmasını beklersiniz. Pek çok uyum ölçüsü, doğru bir model için l'e yakın olması gereken CMIN / DF oranına veya 0'a yakın olması gereken CMIN-DF farkına bağlıdır (IBM Support, 2018).

Tablo 7'de görüldüğü gibi, yapılan çalışmada CMIN değeri 0,000 değerine; DF değeri 0'a eşit olduğu görülmektedir. Bu nedenle ki-kare serbestlik derecesinin (CMIN/DF) uyumlu olduğu görülmektedir.

GFI ve CFI değerlerinin 1,000'a eşit olduğu görülmektedir. Buradan sonuçla uyum indekslerinin iyi bir uyum sergiledikleri görülmektedir.

Modelin serbestlik derecesi sıfır olması, modelin tam tanımlanmış bir model olduğu anlamına gelmektedir. Modelde, veri ve yapısal parametreler arasında bire bir uyum olduğunu göstermektedir. Kısacası, gözlenen değişkenlerin varyans ve kovaryans sayısı, tahmin edilen parametrelerin sayısına eşittir (Bayram, 2010).

Tablo 8. Standartlaştırılmış Regresyon Ağırlıkları (Table 8. Standardized Regression Weights)

\begin{tabular}{lllll}
\hline & & & Tahmin & P \\
\hline Bilgi & $<---$ & $\begin{array}{l}\text { Güvenlik } \\
\text { İklimi }\end{array}$ & 0,622 & $* * *$ \\
\hline Motivasyon & $<---$ & $\begin{array}{l}\text { Güvenlik } \\
\text { İklimi }\end{array}$ & 0,202 & $* * *$ \\
\hline Motivasyon & $<---$ & Bilgi & 0,479 & $* * *$ \\
\hline $\begin{array}{l}\text { Güvenlik } \\
\text { Performansı }\end{array}$ & $<---$ & $\begin{array}{l}\text { Güvenlik } \\
\text { İklimi }\end{array}$ & 0,157 & $* * *$ \\
\hline $\begin{array}{l}\text { Güvenlik } \\
\text { Performansı }\end{array}$ & $<---$ & Motivasyon & 0,492 & $* * *$ \\
\hline $\begin{array}{l}\text { Güvenlik } \\
\text { Performansı }\end{array}$ & $<---$ & Bilgi & 0,279 & $* * *$ \\
\hline
\end{tabular}

*** p değerinin 0.01 'den küçük olduğunu ifade eder. 
Tablo 8'de görüldüğü gibi YEM modelinin standardize regresyon ağırlıklarında her regresyonun anlamlılık düzeyi $\mathrm{p}$ $<0,05$ 'ten küçük olduğu dolayısıyla anlamlı olduğu tespit edilmiştir.

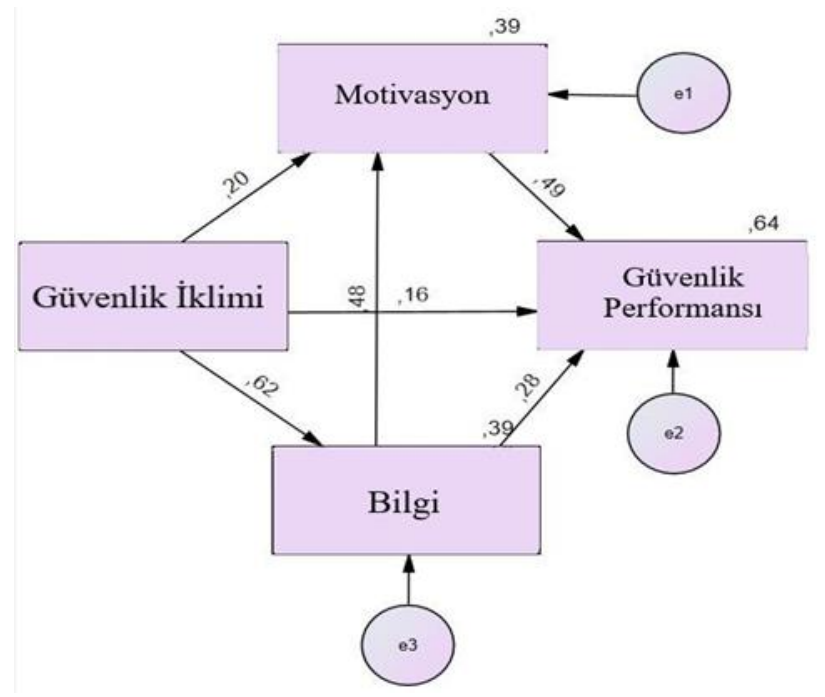

Şekil 4. Uygulanan Modelin Yol Analizi (Figure 4. Path Analysis of the Applied Model)

Şekil 4'te bulunan standardize edilmiş regresyon katsayılarına bakıldığında Güvenlik İklimi ile Motivasyon arasındaki standardize edilmiş regresyon katsayısının 0,20 olduğu; Güvenlik İklimi ile bilgi arasındaki standardize edilmiş regresyon katsayısının 0,62 olduğu; Güvenlik İklimi ile Güvenlik Performansı arasındaki direkt olarak standardize edilmiş regresyon katsayısının 0,16 olduğu görülmektedir. Bilgi ile Motivasyon arasındaki standardize edilmiş regresyon katsayısının 0,48 olarak; Bilgi ile Güvenlik Performansı arasındaki standardize edilmiş regresyon katsayısının 0,28 olduğu görülmektedir. Motivasyon ile Güvenlik Performans1 arasındaki standardize edilmiş regresyon katsayısının 0,49 olarak bulunmuştur.

Şekil 4'te diyagramdan görüldüğü üzere Güvenlik Performansının \%64'lük kısmının Güvenlik İklimi, Motivasyon ve Bilgi tarafindan; Motivasyonun \%39'luk kısmı Bilgi ve Güvenlik İklimi tarafından; Bilgi'nin ise \%62'lik kısmının Güvenlik iklimi ile açıklanabilir olduğu ortaya çıkmıştır. Güvenlik iklimi güvenlik performansını doğrudan etkilediği gibi bilgi ve motivasyon aracılığıyla da güvenlik performansını etkilemektedir. Ayrıca bilgi hem motivasyon aracılığıyla hem de doğrudan güvenlik performansını etkilemektedir.

\subsection{Yapısal Eşitlik Modeli Analizi}

Tablo 9. YEM Uyum Kriterleri ve Indeksleri Tablosu (Table 9. SEM Compliance Criteria and Indexes Table)

\begin{tabular}{llllll}
\hline Model & $\begin{array}{l}\text { CMIN/ } \\
\text { DF }\end{array}$ & CFI & RMSEA & SRMR & P \\
\hline Varsayıla & 3,796 & 0,955 & 0,094 & 0,028 & $*$ \\
\hline
\end{tabular}

\section{n model}

* p değerinin 0,01 'den küçük olduğunu ifade eder.

Tablo 9'a bakıldığında, ki-kare serbestlik derecesinin anlamlı olabilmesi için $0 \leq \mathrm{x}^{2} / \mathrm{sd} \leq 3$ olması gerekmektedir (Bayram, 2010). Modelin değeri ise 3,796 olduğu bulunmuştur. YEM'de birden fazla uyum kriterine bakıldığından uyum kriterlerinin çoğu uyum gösterdiği sürece model kabul edilmektedir (Bayram, 2010). Modelin CFI değeri 0,95 $\leq$ CFI olması modelin uyum gösterdiği kabul edilir (Hu \& Bentler, 1999). Tablo 9'a bakıldığında modelin RMSEA değerine kabul edilebilir uyumu gösterir (RMSE $\leq 0,10$ ) (Browne \& Cudeck, 1992). Tablo 9'da SRMR $\leq 0,05$ olduğu için model iyi uyumu ifade etmektedir (Bayram, 2010). Tablo 9'da görüldüğü gibi modelin YEM ile analizinde parametrelerin çoğu istatistiksel olarak anlamlı bulunmuştur $(\mathrm{p}<0,05)$.

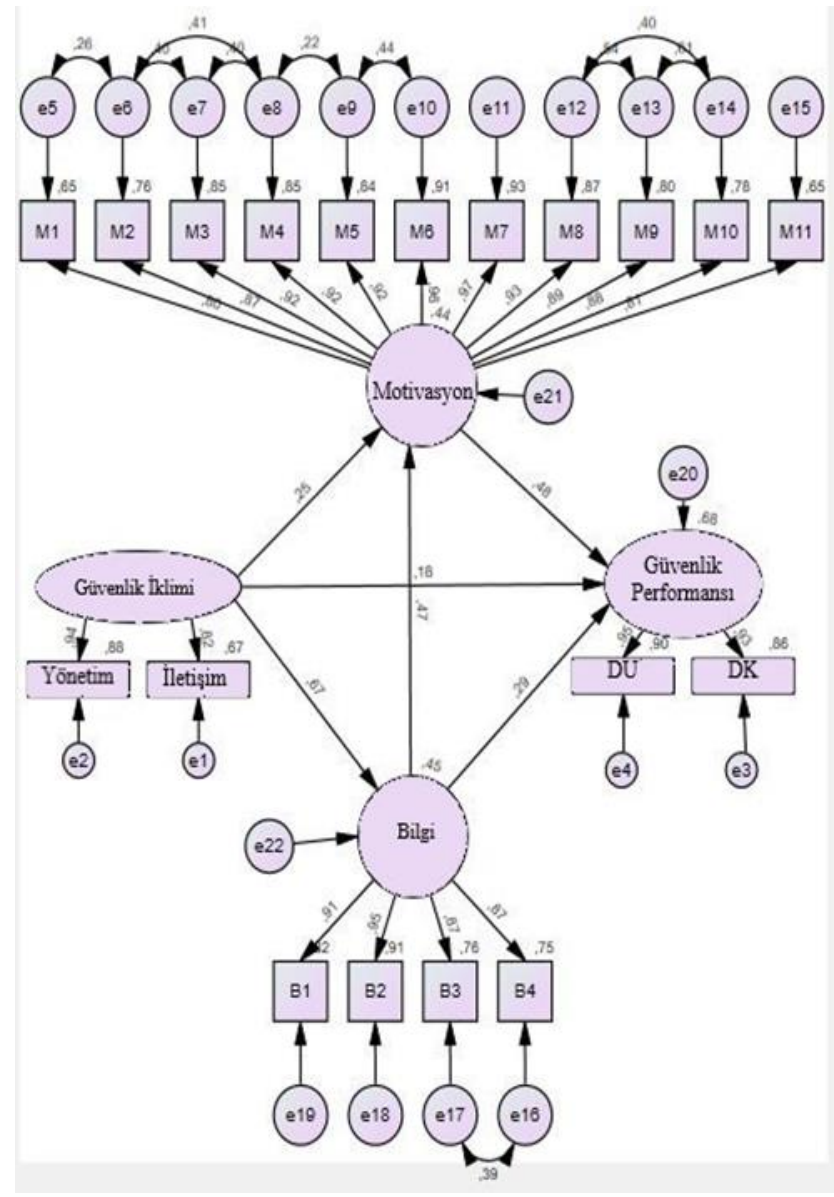

Şekil 5. Modelin YEM Analizde Gösterimi (Figure 5.
Representation of the Model in SEM Analysis)

Şekil 5'e bakıldığında, Güvenlik Performansı gizil değişkeni için faktör yükleri 0,93-0,95 arasında değişmektedir, Güvenlik İklimi gizil değişkeni için faktör yükleri 0,82-0,94 arasında, motivasyon gizil değişkeni için faktör yükleri 0,80-0,97 arasında değişmekte ve bilgi gizil değişkeni için faktör yükleri 0,87-0,95 arasında değişmektedir. Güvenlik performansını gizil değişkeni için açıklanan varyansın \%68'i güvenlik iklimi, bilgi ve motivasyon gizil değişkenlerinin direkt etkisiyle eşzamanlı olarak hesaplanmış ve aynı zamanda bilgi ve motivasyon değişkenlerinin dolaylı etkisi ile güvenlik ikliminin güvenlik 
performansına bir etkisi gözlemlenmiştir. Bulunan bir diğer önemli bulgu ise güvenlik performansını açıklamada motivasyon gizil değiş̧keninin bilgi gizil değişkeninden daha fazla etkiye sahip olduğu saptanmıştır.

\subsection{Düzenleyici (Moderatör) Regresyon Analizi}

\subsubsection{Güvenlik ikliminin güvenlik performanst üzerindeki etkisi cinsiyet üzerinden değerlendirilmesi}

Yapılan kategorik değişken ile moderatör (düzenleyici) regresyon analizinde $P$ anlamlılık düzeyi değeri $p<0,05$ olarak gözlemlenerek anlamlı olduğu saptanmıştır. Tablo 10'da a moderatörü kadını, b moderatörü erkeği temsil etmektedir. Parametreler için kritik oranlara bakıldığında a'dan b'ye olan etki, mutlak değerce 1,96'dan küçük olduğu için (Weston \& Gore, 2006) anlamsız bulunmuştur. Yani güvenlik ikliminin güvenlik performansı üzerindeki etkisi cinsiyete göre değişmemektedir.

Tablo 10. Değişkenler Arasındaki Farklar için Kritik Oranlar (Varsayllan model)(Table 10. Critical Ratios for Differences Between Variables (Default model)

$\mathbf{a}$

a $\quad 0,000$

b

0,846

0,000

\subsubsection{Güvenlik ikliminin güvenlik performansı üzerindeki etkisi eğitim durumu üzerinden değerlendirilmesi}

Tablo 11. Değişkenler Arasındaki Farklar için Kritik Oranlar (Varsayllan model) (Table 11. Critical Ratios for Differences Between Variables (Default model))

\begin{tabular}{lllllll}
\hline & $\mathbf{a}$ & $\mathbf{b}$ & $\mathbf{c}$ & $\mathbf{d}$ & $\mathbf{e}$ & $\mathbf{f}$ \\
\hline $\mathbf{a}$ & 0,000 & & & & & \\
\hline $\mathbf{b}$ & $-0,791$ & 0,000 & & & & \\
\hline c & 0,701 & 1,691 & 0,000 & & & \\
\hline d & $-0,078$ & 0,923 & $-1,177$ & 0,000 & & \\
\hline e & $-1,514$ & $-0,512$ & $-3,414$ & $-2,306$ & 0,000 & \\
\hline f & $-2,529$ & $-1,572$ & $-4,740$ & $-3,766$ & $-1,713$ & 0,000 \\
\hline
\end{tabular}

Yapılan kategorik değişken ile moderatör (düzenleyici) regresyon analizinde $P$ anlamlılık düzeyi değeri $p<0,05$ olarak gözlemlenmiştir. Tablo 11 incelendiğinde, moderatörler $\mathrm{a}=$ ilkokul, $\mathrm{b}=$ ortaokul, $\mathrm{c}=$ lise, $\mathrm{d}=$ ön lisans, $\mathrm{e}=$ lisans, $\mathrm{f}=$ lisansüstü mezuniyeti temsil etmektedir. İlgili tabloya göre güvenlik iklimin güvenlik performansı üzerindeki etkisi eğitim durumuna göre değişmektedir. Bu tabloya göre;
- Güvenlik ikliminin güvenlik performansı üzerindeki etkisi, ilkokul mezunu bireylerin lisansüstüne mezunu bireylere göre daha fazladir.

- Güvenlik iklimin güvenlik performansı üzerindeki etkisi, lise mezunu bireylerin lisans mezunu bireylere göre daha fazladır.

- Güvenlik iklimin güvenlik performansı üzerindeki etkisi, lise mezunu bireylerin lisansüstü mezunu bireylere göre daha fazladır.

- Güvenlik iklimin güvenlik performansı üzerindeki etkisi, ön lisans mezunu bireylerin lisans mezunu bireylere göre daha fazladir.

- Güvenlik iklimin güvenlik performansı üzerindeki etkisi, ön lisans mezunu bireylerin lisansüstü mezunu bireylere göre daha fazladir.

\subsubsection{Motivasyonun güvenlik performansı üzerindeki etkisinin meslek grubu üzerinden değerlendirilmesi}

Tablo 12. Değişkenler Arasındaki Farklar için Kritik Oranlar (Varsayllan model) (Table 12. Critical Ratios for Differences Between Variables (Default model)

\begin{tabular}{lllllll}
\hline & $\mathbf{a}$ & $\mathbf{b}$ & $\mathbf{c}$ & $\mathbf{d}$ & $\mathbf{e}$ & $\mathbf{f}$ \\
\hline $\mathbf{a}$ & 0,000 & & & & & \\
\hline $\mathbf{b}$ & 0,330 & 0,000 & & & & \\
\hline $\mathbf{c}$ & 1,197 & 0,823 & 0,000 & & & \\
\hline $\mathbf{d}$ & $-0,821$ & $-1,122$ & $-2,004$ & 0,000 & & \\
\hline e & 1,893 & 1,495 & 0,714 & 2,680 & 0,000 & \\
\hline f & 1,853 & 1,447 & 0,645 & 2,656 & $-0,089$ & 0,000 \\
\hline
\end{tabular}

Yapılan kategorik değişken ile moderatör(düzenleyici) regresyon analizinde $P$ anlamlılık düzeyi değeri $p<0,05$ olarak gözlemlenmiştir. Tablo 12 'de moderatörler incelendiğinde $\mathrm{a}=$ eğitim, $b=$ sağlık, $c=$ hizmet, $d=$ yapı işleri, $e=$ sanayi ve üretim, $\mathrm{f}=$ serbest meslek sektöründe çalışanları temsil etmektedir. Tablo incelendiğinde motivasyonun güvenlik iklimi üzerindeki etkisi çalışılan sektöre göre değişmektedir. Tablo 12'e göre;

- Motivasyonun güvenlik performansı üzerindeki etkisi, hizmet sektöründe çalışan bireylerin yapı işleri sektöründe çalışan bireylere göre daha fazladır.

- Motivasyonun güvenlik performansı üzerindeki etkisi, yapı işleri sektöründe çalışan bireylerin sanayi ve üretim sektöründe çalışan bireylere göre daha fazladır.

- Motivasyonun güvenlik performansı üzerindeki etkisi, yapı işleri sektöründe çalışan bireylerin serbest meslek sektöründe çalışan bireylere göre daha fazladır.

Yapılan bu araştırmada, güvenlik bilgisinin hem doğrudan hem de dolaylı olarak, motivasyonun ise doğrudan güvenlik performansı üzerine etkisi olduğu saptanmıştır. Benzer bir şekilde Griffin ve Neal (2000) tarafından yapılan bir araştırmada 
da güvenlik bilgisi ve motivasyon, güvenlik performansı ile ilgili sonuçları etkilediği ve ayrıca güvenlik iklimi ile güvenlik performansı arasındaki bağlantıya aracılık ettiği dile getirilmiştir.

Fang, Chen ve Wong'un (2006), yapmış olduğu çalışmada eğitim seviyesi güvenlik iklimi için önemli bir etki faktörüdür. Eğitim düzeyi düşük olan çalışanlar, güvenlik iklimi hakkında diğerlerine göre çok daha az olumlu algılara sahip olduklarını ifade etmişlerdir. Bu çalışmada da güvenlik ikliminin güvenlik performansı üzerindeki etkisi eğitim düzeyi açısından incelenmiştir ve bu etki eğitim seviyelerine göre farklılık göstermektedir. Güvenlik ikliminin güvenlik performansına olan etkisinin eğitim seviyesi düşük olan çalışanlarda daha fazla olduğu görülmüştür. $\mathrm{Bu}$ çalışmaların bulguları göz önünde bulundurulduğunda özellikle eğitim seviyesi düşük olan örgütlerin, güvenlik performansını artırmak için güvenlik iklimine verilen önemi artırmaları gerektiği düşünülebilir.

$\mathrm{Bu}$ çalışmada güvenlik ikliminin, güvenlik performansını direkt olarak pozitif yönlü etkilediği gibi, motivasyon ve bilgi aracılığıyla da pozitif yönlü etkilediği sonucuna varılmıştır. Güvenlik performansı ile ilgili yürütülen diğer çalışmalar incelendiğinde, Hon, Chan ve Yam (2014), tarafindan yapilan çalışmada güvenlik ikliminin, güvenlik katılımı ve güvenlik uyumu (güvenlik performansı) ile pozitif yönde anlamlı bir ilişki olduğunu saptamışlardır. Benzer bir şekilde birçok araştırmada güvenlik iklimi ile güvenlik performansı arasında pozitif bir ilişki bulmuştur (Alruqi, Hallowell \& Techera, 2018; Chen, Jin, \& Soboyejo, 2013; He vd., 2020; Lingard, Cooke, \& Blismas, 2011; Lu \& Yang, 2011). Yapılan bu çalışmalarda ortak bir güvenlik iklimi anketi kullanılmamıştır. Ancak yapılan çalışmaların sonuçlarına bakıldığında güvenlik ikliminin güvenlik performansı üzerinde önemli bir etkisi olduğu görülmektedir.

Yapılan bu çalışmada güvenlik performansına doğrudan etki eden unsurlar arasında motivasyon en yüksek orana sahip olan etkendir. Bununla birlikte sırasıyla bilgi ve güvenlik iklimi de güvenlik performansı üzerinde doğrudan olumlu bir etkiye sahiptir. Benzer bir çalışmada Christian vd., (2009), güvenlik bilgisi ve güvenlik motivasyonu güçlü bir biçimde güvenlik performansı davranışları ile olumlu yönde ilişkisi olduğunu ifade etmişlerdir. Yapılan bir başka araştırmada da güvenlik motivasyonu iş kazası oranı(davranış) ile önemli ölçüde korelasyon gösterdiği saptanmış ve güvenlik motivasyonun iş kazası oranının önemli bir belirleyicisi olduğu ifade edilmiştir. $\mathrm{Bu}$ nedenle, yüksek riskli işlerde güvenlik motivasyonunu artırmak ve iş baskısını azaltmak, kuruluşların iş kazası oranlarını düşürebilecek etkili yollardır (Pordanjani \& Ebrahimi, 2015). Yapılan bu çalışmada motivasyonun güvenlik performansı üzerindeki etkisinin meslek gruplarına göre değişiklik gösterdiği saptanmıştır. - örneğin hizmet sektöründe motivasyonun güvenlik performansına olan etkisi diğer sektörlere oranla daha fazla olduğu tespit edilmiştir.- Bu yüzden güvenlik motivasyonunu artırmaya yönelik çalışmalar sektörel koşullar göz önünde bulundurularak hazırlanmalıdır.

\section{Sonuçlar}

Yapılan bu çalışmada güvenlik performansını doğrudan etkileyen en önemli unsurun motivasyon olduğu belirlenmiştir. Fakat güvenlik iklimi ve bilginin motivasyon üzerinde etkisi bulunduğu için güvenlik performansına dolaylı olarak etki ettiği görülmektedir. Aynı zamanda güvenlik ikliminin bilgi üzerinde e-ISSN: 2148-2683 de güçlü bir etkisi bulunmaktadır. Bu yüzden güvenlik iklimi hem doğrudan hem motivasyon hem de bilgi aracilığıly güvenlik performansına etki etmektedir. $\mathrm{Bu}$ sonuçlardan hareketle güvenlik performansının artmasını sağlamak için bilgi ve motivasyon artırıcı çalışmalar yapılmalıdır. Ayrıca motivasyon bilgi ve güvenlik iklimi birbirinden ayrılmadan bütüncül bir şekilde ele alınmalıdır. İSG bilgi seviyesini artırmak için öğrenim hayatı boyunca müfredat içerisinde ISG eğitimlerine yer verilmelidir. Ek olarak işyerlerindeki ISG eğitimlerinin nitelik ve nicelik bakımından artırılmalıdır. Motivasyon seviyesini artırmak için işyerlerinde ISG yönetim sistemlerini de içeren sosyal uygunluk standartlarının uygulanması ile güvenlik performansı sağlanabilir.

Bununla birlikte yapılan ölçek uyarlamasının kısıtları bulunmaktadır. Ölçekler, işyerleri için geçerli olduğundan dolayı tam zamanlı çalışanlar ve 18 yaşından büyük yetişkin bireyler için uygundur.

Güvenlik kültürü üzerine yapılan çalışmalara bakıldığında Türkiye'de güvenlik kültürü düzeyinin zayıflığına dikkat çekilmiştir (Temur \& Mertoğlu, 2019; Olcay, Temur \& Sakallı, 2021). Ulusal literatürde güvenlik iklimi, güvenlik performans1 belirleyicileri ve bileşenleri konusunda çalışmalarda tam anlamı ile ölçek uyarlaması yapılmamıştır. Bu çalışma ile, yapılan ölçek uyarlaması güvenlik iklimi ve güvenlik performansı ile ilgili yapılacak sonraki çalışmalara 1şık tutabilecek niteliktedir.

\section{Teșekkür}

Yapılan bu çalışma, geçtiğimiz yıl mayıs ayında COVID-19 salgını sebebiyle hayatını kaybeden Serhat TEMUR'a ithaf edilmiştir.

\section{Kaynakça}

Alruqi, W. M., Hallowell, M. R., \& Techera, U. (2018). Safety Climate Dimensions And Their Relationship To Construction Safety Performance: A Meta-Analytic Review. Safety Science, 109, 165-173.

Barbaranelli, C., Petitta, L., \& Probst, T. M. (2015). Does Safety Climate Predict Safety Performance İn Italy And The USA? Cross-Cultural Validation Of A Theoretical Model Of Safety Climate. Accident Analysis \& Prevention, 77, 35-44.

Baron, R. M., \& Kenny, D. A. (1986). The Moderator-Mediator Variable Distinction İn Social Psychological Research: Conceptual, Strategic, And Statistical Considerations. Journal Of Personality And Social Psychology, 51(6), 1173.

Bayram, N. (2010). Yapısal Eşitlik Modellemesine Giriş AMOS Uygulamaları. Ezgi Kitabevi.

Beus, J. M., Payne, S. C., Bergman, M. E., \& Arthur Jr, W. (2010). Safety Climate And İnjuries: An Examination Of Theoretical And Empirical Relationships. Journal Of Applied Psychology, 95(4), 713.

Brislin, Richard W.- LonnerWalter J.- Thorndike Robert M, (1973), Cross Cultural Research Methods, New York, John Wiley- SonsPub.

Browne, M. W., \& Cudeck, R. (1992). Alternative Ways Of Assessing Model Fit. Sociological Methods \& Research, 21(2), 230-258.

Bouargane, L., \& Cherkaoui, A. (2015, October). Towards an explicative model of human cognitive process in a hidden hazardous situation and a cognitive ergonomics intervention in railway environment. In 2015 International Conference 
on Industrial Engineering and Systems Management (IESM) (pp. 968-976). IEEE.

Büyüköztürk, Ş. (2002). Faktör Analizi: Temel Kavramlar ve Ölçek Geliştirmede Kullanımı. Kuram ve Uygulamada Eğitim Yönetimi, 32(32), 470-483.

Campbell, J.P., Gasser, M.B. \& Oswald, F.L. 1996, 'The Substantive Nature Of Performancevariability', İn Individual Differences And Behavior İn Organizations, Ed. K.R. Murphy,Jossey-Bass, San Fancisco.

Cattell, R. B. (1978). The Scientific Use Of Factor Analysis. New York: Plenum.

Chen, Q., Jin, R., \& Soboyejo, A. (2013). Understanding A Contractor's Regional Variations in Safety Performance. Journal Of Construction Engineering And Management, 139(6), 641-653.

Child, D. (2006). The Essentials of Factor Analysis. A\&C Black.

Christian, M. S., Bradley, J. C., Wallace, J. C., \& Burke, M. J. (2009). Workplace Safety: A Meta-Analysis Of The Roles Of Person And Situation Factors. Journal Of Applied Psychology, 94(5), 1103.

Clarke, S. (2006). The Relationship Between Safety Climate And Safety Performance: A Meta-Analytic Review. Journal Of Occupational Health Psychology, 11(4), 315.

Clarke, S. (2010). An İntegrative Model Of Safety Climate: Linking Psychological Climate And Work Attitudes To Individual Safety Outcomes Using Meta-Analysis. Journal Of Occupational And Organizational Psychology, 83(3), 553-578.

Clarke, S., \& Ward, K. (2006). The Role Of Leader Influence Tactics And Safety Climate İn Engaging Employees' Safety Participation. Risk analysis, 26(5), 1175-1185.

Clarke, S., Probst, T. M., Guldenmund, F. W., \& Passmore, J. (2015). The Wiley Blackwell Handbook Of The Psychology Of Occupational Safety And Workplace Health. John Wiley \& Sons.

Comrey, A. L., \& Lee, H. B. (2013). A First Course İn Factor Analysis. Psychology press.

Cooper, M. D. (2000). Towards A Model Of Safety Culture. Safety Science, 36(2), 111-136.

Cooper, M. D., \& Phillips, R. A. (2004). Exploratory Analysis Of The Safety Climate And Safety Behavior Relationship. Journal Of Safety Research, 35(5), 497-512.

Cox, S., \& Cox, T. (1991). The Structure Of Employee Attitudes To Safety: A European Example. Work \& Stress, 5(2), 93106.

Doğan, N., Soysal, S., \& Karaman, H. (2017). Aynı Örnekleme Açımlayıcı ve Doğrulayıcı Faktör Analizi Uygulanabilir Mi? Pegem Atıf İndeksi, 373-400.

Ensari Özay, M , Yılmaz, A , Uçan, R . (2020). Occupational Safety Culture Of Accommodation Sector Employees İn Balıkesir Province: NOSACQ-50 Survey . International Journal of Pure and Applied Sciences , 6 (2) , 186-193.

Eskandari, D., Gharabagh, M. J., Barkhordari, A., Gharari, N., Panahi, D., Gholami, A., \& Teimori-Boghsani, G. (2020). Development of a Scale for Assessing the Organization's Safety Performance Based Fuzzy ANP. Journal of Loss Prevention in the Process Industries, 104342.

Fang, D., Chen, Y., \& Wong, L. (2006). Safety Climate İn Construction Industry: A Case Study İn Hong Kong. Journal Of Construction Engineering And Management, 132(6), 573-584.
Geller, E. Scott (1994), “Ten Principles for Achieving a Total Safety Culture", Professional Safety, 39 (9), American Society of Safety Engineers, pp. 18-25.

Givehchi, S., Hemmativaghef, E., \& Hoveidi, H. (2017). Association Between Safety Leading Indicators and Safety Climate Levels. Journal Of Safety Research, 62, 23-32.

Gorsuch, R. L. (1983). Factor Analysis. Hillsdale,NJ: Erlbaum.

Griffin, M. A., \& Curcuruto, M. (2016). Safety Climate in Organizations. Annual Review of Organizational Psychology and Organizational Behavior, 3, 191-212.

Griffin, M. A., \& Neal, A. (2000). Perceptions Of Safety At Work: A Framework for Linking Safety Climate To Safety Performance, Knowledge, and Motivation. Journal of Occupational Health Psychology, 5(3), 347-358. https://doi.org/10.1037/1076-8998.5.3.347

Guldenmund, Frank W. (2000), "The Nature of Safety Culture: A Review of Theory and Research", Safety Science, Vol. 34, pp. 215-257.

He, C., McCabe, B., Jia, G., \& Sun, J. (2020). Effects Of Safety Climate And Safety Behavior On Safety Outcomes Between Supervisors and Construction Workers. Journal Of Construction Engineering And Management, 146(1), 04019092.

Hofmann, D. A., \& Stetzer, A. (1996). A Cross-Level Investigation Of Factors Influencing Unsafe Behaviors And Accidents. Personnel Psychology, 49(2), 307-339.

Hogarty, K. Y., Hines, C. V., Kromrey, J. D., Ferron, J. M., \& Mumford, K. R. (2005). The Quality Of Factor Solutions in Exploratory Factor Analysis: The Influence of Sample Size, Communality, and Overdetermination. Educational and Psychological Measurement, 65(2), 202-226.

Hon, C. K., Chan, A. P., \& Yam, M. C. (2014). Relationships Between Safety Climate And Safety Performance Of Building Repair, Maintenance, Minor Alteration, and Addition (RMAA) Works. Safety science, 65, 10-19.

Hoyle, R. H. (1995). Structural Equation Modeling: Concepts, Issues, and Applications. Sage.

Hu, L. T., \& Bentler, P. M. (1999). Cutoff Criteria For Fit Indexes In Covariance Structure Analysis: Conventional Criteria Versus New Alternatives. Structural Equation Modeling: A Multidisciplinary Journal, 6(1), 1-55.

International Business Machine (IBM), IBM Support, https://www.ibm.com/support/pages/when-amos-will-notprovide-fit-measures [Last Access: 31.01.2021]

Insag- 15 Report (2002), Key Practical Issues in Strenghtening Safety Culture, A Report by the International Nuclear Safety Advisory Group (Uluslararası Nükleer Güvenlik Danışma Grubu), International Atomic Energy Agency, Vienna.

Jackson, D. L., Gillaspy Jr, J. A., \& Purc-Stephenson, R. (2009). Reporting Practices in Confirmatory Factor Analysis: An Overview And Some Recommendations. Psychological methods, 14(1), 6 .

Kaynak, Z. N. (2012). Yapısal Eşitlik Modelleri, Yayımlanmamış Doktora Tezi, İstanbul Ticaret Üniversitesi Fen Bilimleri Enstitüsü, İstanbul, 27-28.

Khandan, M., Maghsoudipour, M., Vosoughi, S., \& Kavousi, A. (2013). Safety climate and prediction of ergonomic behavior. International journal of occupational safety and ergonomics, 19(4), 523-530.

Kim, E., Sok, S. R., \& Won, C. W. (2021). Factors Affecting Frailty Among Community-Dwelling Older Adults: A MultiGroup Path Analysis According To Nutritional Status. International Journal of Nursing Studies, 115, 103850. 
Kim, S., Kim, P. B., \& Lee, G. (2021). Predicting Hospitality Employees' Safety Performance Behaviors in The COVID19 Pandemic. International Journal of Hospitality Management, 93, 102797.

Kline, P. (1979). Psychometrics and Psychology. London: Acaderric Press.

Kline, P. (2014). An Easy Guide to Factor Analysis. Routledge.

Kline, R. B. (2015). Principles And Practice Of Structural Equation Modeling. Guilford Publications.

Lingard, H., Cooke, T., \& Blismas, N. (2011). Coworkers' Response to Occupational Health and Safety. Engineering, Construction And Architectural Management.

Lu, C. S., \& Yang, C. S. (2011). Safety Climate And Safety Behavior İn The Passenger Ferry Context. Accident Analysis \& Prevention, 43(1), 329-341.

MacCallum, R. C., \& Hong, S. (1997). Power Analysis in Covariance Structure Modeling Using GFI and AGFI. Multivariate Behavioral Research, 32(2), 193-210.

McSween TE. Values based safety processes. 2nd ed. Hoboken, NJ, USA: Wiley; 2003

Mearns, K. J., \& Flin, R. (1999). Assessing the state of organizational safety-culture or climate? Current psychology, 18(1), 5-17.

Neal, A., \& Griffin, M. A. (2002). Safety Climate And Safety Behaviour. Australian Journal Of Management, 27(1_suppl), 67-75.

Neal, A., \& Griffin, M. A. (2006). A Study Of The Lagged Relationships Among Safety Climate, Safety Motivation, Safety Behavior, and Accidents at the Individual and Group Levels. Journal Of Applied Psychology, 91(4), 946.

Neal, A., Griffin, M. A., \& Hart, P. M. (2000). The Impact Of Organizational Climate On Safety Climate And Individual Behavior. Safety Science, 34(1-3), 99-109.

Norusis, M. J. (1994). SPSS Advanced Statistics 6.1. Chicago, IL: SPSS Inc

Olcay, Z. F., Temur, S., \& Sakalli, A. E. (2021). A Research on the Knowledge Level and Safety Culture of Students Taking Occupational Health And Safety Course. Cypriot Journal of Educational Sciences, 16(1), 187-200.

Öner, N. (1996). Türkiye'de Kullanılan Psikolojik Testler: Bir Başvuru Kaynağı, İstanbul: Boğaziçi Üniversitesi Yayınları, 56-63.

Patankar, M. S., \& Sabin, E. J. (2010). The Safety Culture Perspective. In Human Factors in Aviation (pp. 95-122). Elsevier Inc. https://doi.org/10.1016/B978-0-12-3745187.00004-3

Pidgeon, N. 1991. Safety Culture and Risk Management in Organizations. Cross-Cultural Psychology 22: 129-140.

Pordanjani, T. R., \& Ebrahimi, A. M. (2015). Safety Motivation and Work Pressure As Predictors Of Occupational Accidents in the Petrochemical Industry. Health Scope, 4(4).

Reason, J. (1995). A Systems Approach to Organizational Error. Ergonomics, 38(8), 1708-1721.

Sakallı, A. E. (2019). A Tipi ve B Tipi Kişilik Özelliğine Sahip Bireylerde İş Doyumu Ve Kazalanma Arasındaki İlişkinin İncelenmesi. OHS Academy, 2 (1), 11-31 .

Sardeshmukh, S. R., \& Vandenberg, R. J. (2017). Integrating Moderation and Mediation: A Structural Equation Modeling Approach. Organizational Research Methods, 20(4), 721745.

Schumacker, R.E.- R.G. Lomax, (2010), A Beginners's Guide to Structural Equation Modeling, Lawrence Erlbaum Associates, New Jersey.
Uca, N., \& Sümen, H. (2016). Ülkelerin Yolsuzluk Algısının, Lojistik Performansının, Dış Ticaret Hacminin ve Küresel Rekabet İlişkisinin Yapısal Eşitlik Modeli İle İncelenmesi: Kavramsal Model Önerisi (Master's thesis, Maltepe Üniversitesi, Sosyal Bilimler Enstitüsü).

Seo, D. C., Torabi, M. R., Blair, E. H., \& Ellis, N. T. (2004). A Cross-Validation Of Safety Climate Scale Using Confirmatory Factor Analytic Approach. Journal Of Safety Research, 35(4), 427-445.

Sue Cox \& Tom Cox (1991) The Structure Of Employee Attitudes To Safety: A European Example, Work \& Stress, 5:2, 93-106,

Tabachnick, B. G. ve Fidell, L. S. (2007). Using Multivariate Statistics. Boston: Allyn and Bacon.

Temur, S., Mertoğlu, B. ( ) Türkiye ve Çekya Arasındaki Güvenlik Kültürüne Bakış Açısı Üzerine İrdeleme. Ohs Academy, 2.2: 67-76.

Uzunsakal, E., \& Yıldız, D. (2018). Alan Araştırmalarında Güvenilirlik Testlerinin Karşılaştırılması ve Tarımsal Veriler Üzerine Bir Uygulama. Uygulamalı Sosyal Bilimler Dergisi, 2(1), 14-28.

Velicer, W. F., \& Fava, J. L. (1998). Affects Of Variable and Subject Sampling On Factor Pattern Recovery. Psychological Methods, 3(2), 231.

Wallace, J. C., Popp, E., \& Mondore, S. (2006). Safety Climate As A Mediator Between Foundation Climates and Occupational Accidents: A Group-Level Investigation. Journal Of Applied Psychology, 91(3), 681.

Weston, R., \& Gore, P. A. (2006). A Brief Guide to Structural Equation Modeling. The Counseling Psychologist, 34(5), 719-751.

Ying, L., Zhijia, H., \& Lianbao, L. (2012). Motivation Mechanism Of Accident Prevention in Coal Mine. Procedia Engineering, 43, 174-179.

Zohar, D. (1980). Safety Climate in İndustrial Organizations: Theoretical And Applied Implications. Journal Of Applied Psychology, 65(1), 96.

Zohar, D. (1980). Safety Climate in Industrial Organizations: Theoretical And Applied Implications. Journal Of Applied Psychology, 65(1), 96.

Türkmenoğlu, C. (2015). Türkçe Metinlerde Duygu Analizi. (Yüksek Lisans Tezi). İstanbul Teknik Üniversitesi Fen Bilimleri Enstitüsü.

Ye, X. Li, S. Yang, X. Qin, C. (2016). Use of Social Media For The Detection and Analysis of Anfectious Diseases in China. ISPRS Int. J. Geo-Inf., 5, 156.

Widener, M.J. Li, W. (2014). Using Geolocated Twitter Data To Monitor The Prevalence of Healthy and Unhealthy Food References Across The US. Appl. Geogr., 54, 189-197.

Wilson, T., Wiebe, J. Hoffmann, Pmesa. (2005). Recognizing Contextual Polarity in Phrase-Level Sentiment Analysis. In Proceedings of The Conference on Human Language Technology and Empirical Methods in Natural Language Processing, pp. 347-354. Association for Computational Linguistics. 